\title{
Recall and recognition of verbal paired associates in early Alzheimer's disease
}

\author{
G.J. LOWNDES,${ }^{1,2,3}$, M.M. SALING,${ }^{1}$ D. AMES,${ }^{2}$ E. CHIU, 2 L.M. GONZALEZ, ${ }^{3}$ \\ AND G.R. SAVAGE ${ }^{3,4}$ \\ ${ }^{1}$ Department of Psychology, University of Melbourne, Parkville, Australia \\ ${ }^{2}$ Academic Unit of Psychiatry of Old Age, University of Melbourne, Kew, Australia \\ ${ }^{3}$ School of Psychology, Psychiatry and Psychological Medicine, Monash University, Clayton, Australia \\ ${ }^{4}$ Macquarie Centre for Cognitive Science (MACCS), Macquarie University, Sydney, Australia
}

(Received July 10, 2007; Final Revision March 14, 2008; Accepted March 21, 2008)

\begin{abstract}
The primary impairment in early Alzheimer's disease (AD) is encoding/consolidation, resulting from medial temporal lobe (MTL) pathology. AD patients perform poorly on cued-recall paired associate learning (PAL) tasks, which assess the ability of the MTLs to encode relational memory. Since encoding and retrieval processes are confounded within performance indexes on cued-recall PAL, its specificity for AD is limited. Recognition paradigms tend to show good specificity for AD, and are well tolerated, but are typically less sensitive than recall tasks. Associate-recognition is a novel PAL task requiring a combination of recall and recognition processes. We administered a verbal associate-recognition test and cued-recall analogue to 22 early AD patients and 55 elderly controls to compare their ability to discriminate these groups. Both paradigms used eight arbitrarily related word pairs (e.g., pool-teeth) with varying degrees of imageability. Associate-recognition was equally effective as the cued-recall analogue in discriminating the groups, and logistic regression demonstrated classification rates by both tasks were equivalent. These preliminary findings provide support for the clinical value of this recognition tool. Conceptually it has potential for greater specificity in informing neuropsychological diagnosis of AD in clinical samples but this requires further empirical support. (JINS, 2008, 14, 591-600.)
\end{abstract}

Keywords: Memory, Learning, Detection, Dementia, Neuropsychology, Associative

\section{INTRODUCTION}

The clinical emergence of Alzheimer's disease (AD) is typically heralded by an insidious and progressive tendency to forget recent day-to-day events, such as conversations. Such events comprise various sensory, emotional, and semantic attributes that are initially processed by different regions of the brain. The rapid formation of lasting associations between these attributes underpins normal memory formation and represents a fundamental role of the medial temporal lobe (MTL), which typically undergoes neurodegenerative changes early in the course of developing $\mathrm{AD}$ (Braak \& Braak, 1991; Hyman et al., 1986). Severe episodic memory impairment has been consistently reported as an early sign of emerg-

Correspondence and reprint requests to: Georgia Lowndes, School of Psychology, Psychiatry and Psychological Medicine, Building 17, Monash University, VIC 3800, Australia. E-mail: georgia.lowndes@med. monash.edu.au ing AD (Elias et al., 2000; Grady et al., 1988), and typically represents the most impaired cognitive domain.

With the advent of pharmacotherapy for $\mathrm{AD}$, which is most efficacious in the early stages of the disease process (Brookmeyer et al., 1998; Giacobini, 2001; Michel et al., 2001), considerable research effort has been directed toward facilitating earlier diagnosis of AD. Hodges (1998) commented that research on dementia has demonstrated that many of AD's diagnostic differentials have their own individual neuropsychological signature (i.e., pattern of cognitive strengths and weaknesses), particularly in the early stages of these conditions. The progressive emergence of clinical signs generally reflects the distribution of underlying neuropathological changes associated with each condition (e.g., frontotemporal dementia, Lewy Body dementia) Whereas the majority of these differentials have "memory impairment" as a cardinal feature of their neuropsychological profile when the term is used broadly, they often differ 
neuropathologically from $\mathrm{AD}$, in that MTL structures are essentially intact or are significantly less affected in their early stages in comparison to that seen in early AD.

Considerable research has been targeted toward characterizing the early memory impairment in Alzheimer-like and non-Alzheimer forms of dementia. The memory impairment in $\mathrm{AD}$ has been characterized in terms of defective encoding/ consolidation because of early MTL damage (Braak \& Braak, 1991; Hyman et al., 1986), rather than an inability to access or retrieve material from memory (Albert, 1981; Greene et al., 1996; Zec, 1993), although inefficient memory retrieval processes may pose a further source of impairment in $\mathrm{AD}$ (Dalla Barba, 1997). As such, probable AD patients characteristically perform below healthy controls on memory tests requiring recall or recognition of recently presented material (Greenaway et al., 2006; Greene et al., 1996; Hodges \& Patterson, 1995; Locascio et al., 1995; Ribeiro et al., 2007; Tierney et al., 2001). Memory impairment in many non-Alzheimer dementias (e.g., depression, vascular dementia, alcohol related dementia, Parkinson's disease), on the other hand, involves relative difficulty in retrieving information from memory rather than encoding/consolidating the information in the first place. In these patient groups recognitionbased memory performance tends to be considerably less impaired than performance on recall tests (e.g., Lachner et al., 1994; Mormont et al., 2003; Tierney et al., 2001), as the recognition format is believed to circumvent effortful retrieval demands (e.g., Butters et al., 1985).

Item-based recognition tests, involving the discrimination of familiar targets from unfamiliar (i.e., novel) distractors, have not proven to be as sensitive to the early stages of AD as delayed recall measures (Dalla Barba, 1997; Lipinska \& Backman, 1997; Tierney et al., 1996; Welsh et al., 1991). In some studies of recognition memory where statistically significant group differences have been reported between $\mathrm{AD}$ patients and control groups, the effect size of the difference is so small that the clinical significance of the difference is questionable (e.g., 9.05 vs. 9.77 out of a total score of 10 words in Chen et al., 2000). Item-recognition measures have been reported as lacking sensitivity for MTL pathology in patients who are considered amnesic using other measures (Reed \& Squire, 1997). Lesion and functional imaging studies support that item-recognition is less dependant on "higher-order" MTL structures like the hippocampus than recall-based measures (Mayes et al., 2002; Montaldi et al., 2006). Item-recognition measures are also commonly affected by the occurrence of ceiling effects in control groups (Hodges, 2000; Piercy \& Huppert, 1972; Welsh et al., 1994).

Rather than relying on existing measures of recall and recognition memory with their established limitations, we have argued that researchers and clinicians should be striving to develop more sensitive and specific diagnostic tools for detecting the signature memory deficits present in preclinical AD (Lowndes \& Savage, 2007). The most widely accepted theory of hippocampal functioning is that it receives, actively binds together and encodes the complex relational structure of personal experiences (Cohen et al., 1999; Henke et al., 1997; Wallenstein et al., 1998). Paired associate learning (PAL) tasks assess the ability to rapidly form and remember associations between attributes of an experience, and they are sensitive to MTL dysfunction (Cohen \& Eichenbaum, 1993). On theoretical and empirical grounds, PAL tests would seem an ideal choice for detecting the MTL-based memory impairment characteristic of early $\mathrm{AD}$, and the paradigm has previously been shown to be sensitive in the preclinical stages of $\mathrm{AD}$ (Fowler et al., 2002; Lee et al., 2003; Swainson et al., 2001). Standardized PAL tasks are typically administered using a cued-recall format, however, and many healthy elderly people find this paradigm difficult (Dunlosky \& Hertzog, 1998; Salthouse, 1994, 1995), as do memory impaired patients without MTL damage, including those with depression (Golinkoff \& Sweeney, 1989) and a range of other neurological conditions (Kinsbourne \& Winocur, 1980; Salmond et al., 2005; Squire \& Shimamura, 1986). Although cued-recall PAL may be sensitive to early $\mathrm{AD}$, poor performances are not necessarily because of MTL dysfunction, rendering its clinical usefulness as tool for detecting AD unacceptably poor because of its low specificity.

Minimal research has been conducted on the ability of the associate-recognition paradigm to discriminate $\mathrm{AD}$ from non-AD related memory impairment (see Gallo et al., 2004; Lee et al., 2003). Associate-recognition involves pairedassociate learning and recognition that a pair of items occurred together in a previously presented list. For example, in verbal variants participants learn a list of word pairs (e.g., horse-forest, ship-seat) and must then discriminate between the intact pairs (e.g., horse-forest) and rearranged pairs (e.g., horse-seat). The paradigm should be highly sensitive to the binding processes carried out by the MTL, while being less dependent on effortful memory retrieval processes than cued-recall PAL because there is no requirement to explicitly retrieve the individual words from the learning episode. In other words, associate-recognition should be as sensitive to AD as cued-recall PAL tasks, but it may have the benefit of being more specific to MTLrelated memory impairment than cued-recall PAL. A number of researchers have suggested that associate-recognition tests may also be more sensitive to the MTL as a functional unit than item-recognition tests. Being fundamentally relational in nature, they require the recollection of more contextual information from the original learning event and therefore load more heavily on hippocampal processes than item-recognition (Aggleton \& Shaw, 1996; Davachi, 2006; Mayes et al., 2004; Tulving \& Markowitsch, 1998; VarghaKhadem et al., 1997).

On this background, the first aim of the current study was to compare the ability of verbal associate-recognition and traditional verbal cued-recall PAL to differentiate a group of early $\mathrm{AD}$ patients from healthy elderly (HE) participants. This comparison represents a critical first step in establishing the paradigm's broader clinical utility. We also investigated the effect of imageability of the test stimuli in 
discriminating AD patients from elderly controls. A concreteness variable was introduced in order to parallel a concrete/abstract sub-structuring apparent in the PAL subtest of early versions of the Wechsler Memory Scale. Paivio et al. (2000) have shown that the ability to generate interactive visual images facilitates verbal PAL performance, independently from the effect of stimulus relatedness. Savage et al. (2002) established that abstract pairs were less easily learned in two samples of epileptic patients (i.e., the typical concreteness effect was observed; e.g., Paivio, 1991), and the manipulation served here to stratify predicted level of difficulty experienced in learning the pairings.

It was hypothesized that $\mathrm{AD}$ patients would perform as poorly on the associate-recognition test, relative to their healthy peers (i.e., to account for differences in the baseline guessing rate), as they would on the cued-recall version establishing the sensitivity of this novel recognition paradigm to early $\mathrm{AD}$. We also hypothesized that at an individual level of analysis, associate-recognition would demonstrate similar sensitivity and specificity as cuedrecall. Specificity was hypothesized to be similar across the groups as the control participants were expected to perform relatively well on cued-recall PAL, as they were included in the study on the basis of performing within the average range on a free-recall memory task. If sensitivity and specificity of the tasks were similar, this would support the idea that associate-recognition may be a viable alternative to traditional cued-recall PAL. We hope this would encourage further development and research into this paradigm as it should have greater specificity in discriminating MTL from non-MTL forms of memory disorder, in principle. Finally, it was suspected that performance on the abstract stimuli in the tests might discriminate the $\mathrm{AD}$ group from the healthy elderly better than the concrete stimuli, because abstract stimuli are generally more difficult to encode according to the Dual Code Theory (Paivio, 1991).

\section{METHOD}

\section{Participants}

The final AD sample consisted of 22 patients diagnosed with probable AD according to the NINCDS-ADRDA diagnostic criteria (McKhann et al., 1984). Six additional patients were excluded from the study as they failed to complete the full assessment (four failed to complete the Cued-Recall PAL task and two withdrew from the study prematurely). The clinical diagnoses of AD were made by experienced psychogeriatricians (authors DA and EC). Eighty-two percent (18 of 22 of patients) had structural neuroimaging to rule out alternative causes for the patients' dementia (e.g., stroke, tumor, hydrocephalus). They were recruited from a number of hospital and private clinics in Melbourne, Australia, with approval from the human research ethics committees of the relevant institutions.
Patients had a Mini-Mental Status Examination (MMSE; Folstein et al., 1975) score equal to or above 20 and were therefore classifiable as having "mild AD" (mild impairment $=$ MMSE score $\geq 20$; Folstein et al., 1975). None were eligible for a diagnosis of depression according to the Montgomery-Asberg Depression Rating Scale (MADRS; Montgomery \& Asberg, 1979) using a cut-off of 15 as advised by Leentjens et al. (2000), or the Geriatric Depression Scale-short form (GDS; Burke et al., 1991) using a cut-off of eight as advised by Yesavage et al. (1983). All patients spoke English as their first language and had no current psychiatric illness, or history of neurological illness, cardiac arrest, cardiac surgery or head injury. Patients were not excluded based on taking cognition-enhancing medication at the time of the assessment (e.g., ACE inhibitors).

The healthy elderly (HE) comparison sample consisted of 50 participants recruited from retirement villages around Melbourne. Participants denied memory or other cognitive impairment, and scored above 25 on the MMSE. Participants were excluded if they reported current psychiatric illness or a history of neurological illness, cardiac arrest, drug abuse or dependence, or current use of medication with a detrimental cognitive effect (e.g., benzodiazepines; $n=2$ ). Participants were also excluded if they presented with a hearing impairment or visual impairment that impacted on their ability to complete the assessment. All participants spoke English as their first language. Six participants were excluded based on performing at a level more than one standard deviation below the mean on one of the following tests: Full-Scale IQ (FSIQ) predicted from the National Adult Reading Test (NART; Nelson \& Willison, 1991), the Hopkins Verbal Learning Test-Revised (HVLT-R; Benedict et al., 1998), or the Vocabulary or Digit Span subtests of the Wechsler Adult Intelligence Scale-Third Edition (Wechsler, 1997). Participants with clinically significant depressive symptoms indicated on the GDS (Burke et al., 1991) were also excluded from the study. See Table 1 for further demographic information regarding the $\mathrm{AD}$ and $\mathrm{HE}$ samples.

\section{Materials}

Two stimulus lists of eight semantically/associatively unrelated word pairs were used. Presentation order of these stimulus lists was counterbalanced across AssociateRecognition (A-R) and Cued-Recall (C-R) test administrations. Four of the word-pairs in each stimulus list were highly imageable or concrete (e.g., horse-forest) and four were less imageable or abstract (e.g., open-fresh). The materials were adapted from those used by Savage et al. (2002), who investigated PAL in patients with temporal lobe epilepsy.

For the purposes of recognition testing, the first (cue) word of each pair was presented at the top of each page of a stimulus booklet to cue participants' recognition of the second (target) word in the pair. Four alternative target words (i.e., one target and three foils) were listed below the cue, 
and cues and targets were always within-class alternatives with respect to imageability (i.e., concrete cues were lists only with concrete target alternatives). See Fig. 1 for an example of two pages from the stimulus booklet. The battery also included background and screening cognitive measures to ensure the participants fulfilled the inclusion criteria for the study (e.g., MMSE, NART, HVLT-R, GDS, MADRS, WAIS-III Vocabulary and Digit Span subtests).

\section{Procedure}

After providing voluntary informed consent, all participants were assessed over two sessions scheduled one week apart. The A-R test was administered in the first session (to minimize potential interference from the concurrently administered HVLT-R on memory recall) and the C-R analogue was always presented in the second session. The general procedure for the administration of these tests was identical and involved reading aloud a set of standardized instructions, then providing a short practice trial, and an example of a verbal and visual strategy that could be used to enhance learning (e.g., Dunlosky \& Hertzog, 1998).

The list of eight word-pairs was read aloud at the rate of one pair every five seconds. Immediate recognition or cuedrecall was tested after each of three list presentations (each of which contained a different fixed order of items). In the recognition test phases, participants were presented with successive pages of the recognition booklet and asked to identify which of four items had been previously paired with the cue item at the head of the page. This is a novel variant of associate-recognition, which typically involves a two-choice or yes/no format within which the target and rearranged pairings are presented. Our design was constructed to emulate the sequential presentation of cuedrecall PAL with the cue presented initially, followed by recall of the target second word. No time limit was set for responding to each item, but participants were encouraged to guess after five seconds. Immediate feedback was given for each item, with the target word-pair identified when
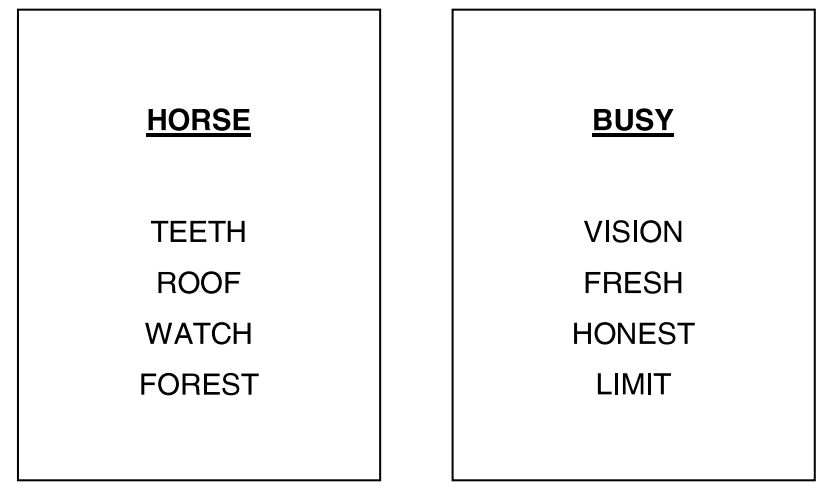

Fig. 1. Example of two pages from the final version of the stimulus book (Left panel: concrete stimuli only. Right panel: abstract stimuli only) errors were made. After a 30-minute filled delay the final recognition or cued-recall test was administered, without representing the stimulus list or feedback.

\section{Data Analyses}

Statistical significance was adjusted according to Bonferroni criteria (i.e., .05/number of comparisons). Data from the alternate stimulus forms, initially counterbalanced across the test formats, were combined in the main analyses. For each participant, the number of correct responses for the four concrete and the four abstract pairs were summed for each learning trial and the delay condition. Performance on the concrete and abstract stimuli were initially analyzed and presented together and then separately.

To investigate which PAL paradigm best predicted incident $\mathrm{AD}$ we conducted stepwise forward entry logistic binomial regression analyses using participants' Total Learning scores (sum of learning trials 1 to 3 ; score range $=$ $0-24)$ for each paradigm. The regression was then repeated using participants' Delay scores (score range $=0-8$ ) from each paradigm.

\section{RESULTS}

\section{Demographic Characteristics of the Samples}

From Table 1, there was no significant difference between the AD and the HE groups in terms of Age, GDS score, or Digit Span scaled score, all $F \mathrm{~s}<1$, or predicted FSIQ score, $F(1,70)=2.99, p>.01, \eta^{2}=0.04$; there was small trend for HE participants to achieve higher Vocabulary scaled scores, $F(1,69)=4.18, p=.05, \eta^{2}=0.06$. As expected the AD sample performed reliably lower than the HE sample on the MMSE, $F(1,70)=83.07, p<.001, \eta^{2}=.55$, HVLT-R Total Learning index, $F(1,71)=129.74, p<.01, \eta^{2}=$ 0.65 , and the HVLT-R Delay index, $F(1,71)=148.38, p<$ $.01, \eta^{2}=0.68$.

\section{Effect of Test Format (A-R vs. C-R) on PAL Performance}

Figure 2 presents means for the A-R and C-R PAL test formats for the AD and HE groups. The HE group performed considerably better than the $\mathrm{AD}$ group on both test formats, $F(1,70)=195.02, p<.01, \eta^{2}=0.74$. Both groups performed better on the A-R format than the $\mathrm{C}-\mathrm{R}$ analogue, $F(1,70)=37.40, p<.01, \eta^{2}=0.35$. Importantly, no interaction was found between Test Format and Group, $F(1,70)=$ $0.30, p>.01, \eta^{2}<0.01$, indicating that the A-R test discriminated the $\mathrm{HE}$ group from the $\mathrm{AD}$ group as effectively as the more traditional $\mathrm{C}-\mathrm{R}$ recall version.

\section{Classification Accuracy by A-R and C-R Paradigms using Logistic Regression}

Stepwise logistic regression analyses were conducted to assess the diagnostic usefulness of the two tests. Firstly, the 
Table 1. AD and HE group means (and $S D$ s) on background screening measures

\begin{tabular}{|c|c|c|c|c|}
\hline \multirow[b]{2}{*}{ Age } & \multicolumn{2}{|c|}{$\mathrm{AD}(N=22)$} & \multicolumn{2}{|c|}{$\operatorname{HE}(N=50)$} \\
\hline & 79.6 & $(9.2)$ & 78.5 & $(6.7)$ \\
\hline $\operatorname{MMSE}^{* *}$ & 24.1 & (2.7) & 28.5 & (1.3) \\
\hline GDS & 2.5 & $(1.8)$ & 2.5 & $(1.7)$ \\
\hline Predicted FSIQ* & 104.1 & $(12.9)$ & 108.6 & (8.6) \\
\hline HVLT-R Total Learning $* * \dagger$ & 6.8 & (13.4) & 67.3 & $(23.2)$ \\
\hline HVLT-R Delay**† & 4.8 & (11.1) & 63.7 & (21.4) \\
\hline Vocabulary $^{\mp}$ & 10.5 & $(3.6)$ & 11.8 & $(1.9)$ \\
\hline Digit Span ${ }^{\mp}$ & 11.3 & (3.5) & 12.1 & (3.3) \\
\hline
\end{tabular}

$* * p<.001, \dagger$ percentile score, ${ }^{\mp}$ scaled score.

A-R Total Learning score was entered into the model alone and its classification accuracy was significant at $95.8 \%$ (3 misclassifications out of 72 participants; $\chi^{2}=67.10, d f=$ $1, p<.001)$. The $\mathrm{C}-\mathrm{R}$ Total Learning index was then entered into the model and it significantly improved classification to $97.2 \%$, reducing misclassifications to 2 participants $\left(\chi^{2}=\right.$ 9.85, $d f=1, p<.01)$. These indexes were then reentered into the model in the reverse sequence and the C-R Total Learning Index demonstrated a classification accuracy of 93.1\% (5 misclassifications out of 72 participants; $\chi^{2}=$ 68.20, $d f=1, p<.001)$. When A-R Total Learning was entered it significantly improved classification to $97.2 \%$, reducing misclassifications to $2\left(\chi^{2}=8.74, d f=1, p<\right.$ $.01)$. As we were conceptually interested in the relative diagnostic specificity of the tests, we compared their specificity while clamping the same sensitivity index. A sensitivity of 0.86 (i.e., 19 out of 22 AD patients) was chosen as this cut-off was easily indexed from both tests. We found that at this sensitivity index, the A-R test provided a specificity of 1.0 and the C-R test an index of 0.96 (2 misclassifications out of 50).

Regression analyses were repeated for the Delay index scores of both tests. When A-R Delay index was entered into the model its classification accuracy was significant at $88.9 \%$ (8 misclassifications out of $72 ; \chi^{2}=58.37, d f=1$, $p<.001)$. When $\mathrm{C}-\mathrm{R}$ delay was entered it significantly improved classification to $95.8 \%$, reducing misclassifications to 3 participants $\left(\chi^{2}=14.39, d f=1, p<.001\right)$. When the entry sequence was reversed the C-R Delay index classification accuracy was $95.8 \%$ with 3 cases misclassified $\left(\chi^{2}=68.33, d f=1, p<.001\right)$. When the A-R index was added, it significantly improved the classification accuracy but did not lead to the reclassification of any cases and hence the overall model accuracy remained at $97.2 \%$ with 2 cases misclassified $\left(\chi^{2}=4.34, d f=1, p<.05\right)$.

\section{Effect of Stimulus Imageability on PAL Performance}

Data presented in Fig. 2 were reanalyzed to investigate the effect of Stimulus Imageability on PAL performance. For each participant, the number of correct responses for the four concrete and the four abstract pairs were summed separately for each Learning Trial and Delay.

From Panel A in Fig. 3, it is clear that the HE group benefited more from the imageability of the concrete stimuli than did the AD patients during the A-R test; the Stimulus Imageability by Group interaction was significant, $F(1,70)=19.48, p<.01, \eta^{2}=0.22$. There was no threeway interaction between Stimulus Imageability, Trial, and Group, $F<1$. In Panel B the same pattern emerged for C-R data where the HE group benefited considerably more from the imageability of the concrete stimuli than did the AD patients, for the interaction, $F(1,70)=53.18, p<.01, \eta^{2}=$ .43; again, no three-way interaction was found, $F<1$. Comparison across the two panels clearly indicates that the difference in performance between the $\mathrm{AD}$ and $\mathrm{HE}$ groups is much larger for the concrete pairs (presented in bold lines) than for the abstract pairs (presented in dashed lines) using both A-R and C-R tests formats.

\section{DISCUSSION}

Verbal associate-recognition is a relational memory paradigm not widely used as a tool for the detection of early AD. This study clearly demonstrates that a verbal associaterecognition paradigm, containing arbitrarily associated words, can be as effective as a cued-recall analogue for discriminating patients in the early stages of AD from healthy elderly people. This result was found both at a group and individual level of analysis. Further analysis revealed the healthy elderly sample performed exceptionally well on the concrete stimuli in both versions of the PAL task but relatively poorly (and close to the AD group's average performance) on the abstract stimuli in both test conditions. AD patients performed poorly on concrete and abstract word-

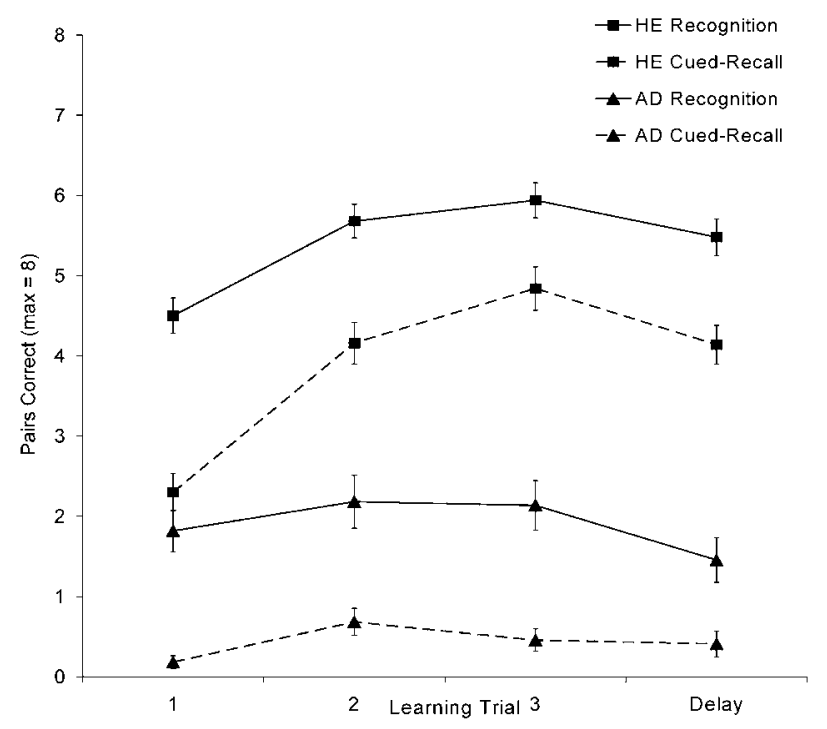

Fig. 2. $A D$ and $H E$ group mean results for the $A-R$ and $C-R$ PAL tests (error bars indicate SEs). 


\section{Panel A}

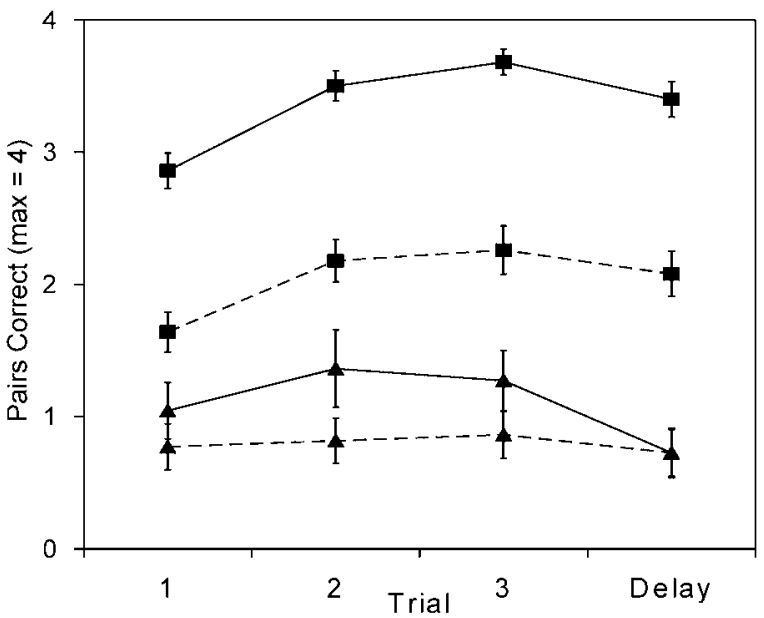

\section{Panel B}

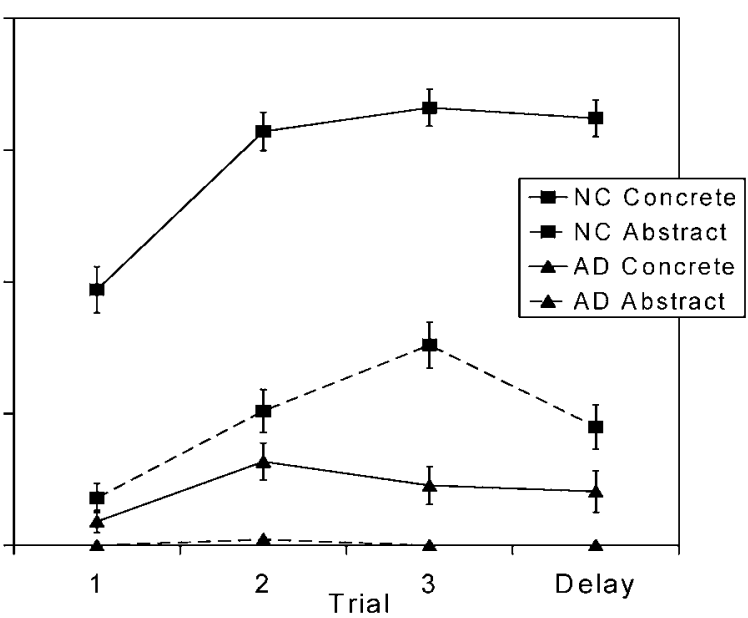

Fig. 3. AD and HE group mean results for the Arbitrary-Recognition (Panel A) and Cued-Recall (Panel B) tests with concrete and abstract pairs presented separately within panels (error bars indicate SEs).

pairs in both PAL test conditions. This finding suggests that a verbal associate-recognition task containing all concrete and no abstract stimuli may demonstrate even greater discriminatory power, warranting further investigation.

In the current study, the AD patients performed very poorly on the Associate-Recognition and Cued-Recall PAL tests in comparison to the healthy elderly group. Overall, their recognition performance was only marginally superior to their cued-recall performance, a difference easily attributable to the $25 \%$ chance-guessing rate in the recognition condition. Furthermore, there was no evidence of learning in the AD group with repeated exposure to the material in either of the PAL test conditions. This finding is consistent with impaired ability to encode/consolidate new information in early AD (Greene et al., 1996), even in those early AD patients taking ACE inhibitors.

For memory tasks to be clinical efficacious they must have the capacity to discriminate impaired from nonimpaired people not only at a group level but also at the individual level. The discrimination accuracy of the two tests in the current study were essentially equivalent at the individual level of analysis; recognition was marginally superior to the cued-recall analogue using Total Learning scores, whereas the reverse was true when delayed recognition/ recall scores were the basis for comparison. On delay, however, the range of scores for comparison was limited from 0 to 8 , and the higher baseline guessing rate in the recognition test lifted average performance of all participants well above zero further reducing the range of scores. Further research may demonstrate that the inclusion of additional items in the delay trial of the associate recognition task may increase its discrimination accuracy. This could include representations of the initial cue words, with target second words flanked by alternative distractors (taken from the original stimulus list).
It is widely documented that recall measures are more sensitive to the early stages of AD than commonly-used item-recognition tasks. It has been suggested that even amnesics perform disproportionately worse on recall measures because of the fact that recognition tests are generally easier (Reed \& Squire, 1997). This finding was not replicated in the current study comparing associate-recognition and cued-recall PAL. Recall may be more dependent than recognition on frontally-mediated executive functions, such as organized search and retrieval (Bunce, 2003; Quamme et al., 2004). Dependence on these non-MTL retrieval processes could render cued-recall PAL less capable of discriminating patients with memory encoding impairments (i.e., early AD) from patients with memory retrieval impairments. This is clearly an area for further research as non-AD participants in the current study were not memory impaired.

The degree to which participants were required to engage in memory search and retrieval processes during the Associate-Recognition test is unclear from this study. Research has suggested that associate-recognition may represent a hybrid of processes typically involved in recall and recognition (Gronlund \& Ratcliff, 1989; Nobel \& Shiffrin, 2001). The Associate-Recognition test supposedly requires the recollection of quite specific contextual information from the initial learning episode, in order to ascertain which initial word was paired with which second word in the stimulus list. In contrast with the Cued-Recall test, however, the content of the learning episode (i.e., the actual words) did not need to be retrieved, as the words were presented within the framework of the test. On this basis, the AssociateRecognition test would have conceivably placed less demand on memory search and retrieval processes than the cuedrecall version. A reduction in the efficiency of these same memory retrieval processes is widely agreed to occur with healthy aging (Burke \& Light, 1981; Howard et al., 1991). 
This may explain why the Associate-Recognition test's diagnostic specificity was marginally higher than the CuedRecall test using Total Learning scores when the sensitivities of the two tests were matched at $86 \%$.

To identify AD in the preclinical stages of disease, where different MTL structures may be variably affected, recognition tests need to be especially sensitive to the functional integrity of the MTL as a whole. Associate-Recognition tests, involving a combination of both familiarity-based and recollective memory processes, are likely to be highly sensitive to the integrity of the MTL as a functional unit. Yonelinas (1994, 1997, 2001) argued that cognitive, neuropsychological, and neuroimaging studies indicate that recognition judgments based on familiarity alone and those requiring some recollection of the learning event are "behaviorally, neurally, and phenomenological distinct memory retrieval processes" (Yonelinas et al., 2001, p. 1363). Whereas some support for an opposing view has been found, that the hippocampus is important for supporting both familiarity and recollection (e.g., Norman \& O'Reilly, 2003; Wixted \& Squire, 2004), this conceptualization would predict that early AD patients should perform poorly on recall and familiaritybased tasks and this is not always the case (Dalla Barba, 1997; Karlsson et al., 2003; Westerberg et al., 2006).

Another finding of this study was the superiority of concrete or highly imageable word pairs in discriminating early AD patients from healthy elderly participants within PAL. Both concrete and abstract stimuli were initially included in the stimulus lists to stratify level of difficulty. It was suspected that abstract stimuli might be more sensitive to early AD than concrete stimuli, as abstract stimuli are generally more difficult to encode according to the Dual Code Theory (Paivio, 1991). However, this was not uniformly the case as the AD group performed similarly poorly on both concrete and abstract pairs. The fact that the healthy elderly group performed considerably worse on the abstract pairs than concrete pairs resulted in the two groups performing most disparately on the concrete pairs, raising doubts about the utility of including abstract stimuli in associate-learning tasks developed for use in elderly populations.

One interpretation of the lack of concreteness effect for the $\mathrm{AD}$ group is that like the healthy elderly, they were more successful at formulating mental images for the concrete pairs than the abstracts (despite being provided with verbal and visual strategies), but they were less able to encode or bind the images into memory because their MTL was damaged. In support of this idea, Jones (1974) reported that during verbal PAL tests, the amnesic patient HM who had undergone bilateral medial temporal resections was able to form and describe mental images he invoked to facilitate his memory for the word-pair associates. The images he produced on different learning trials changed, however, without him showing any indication that he had previously produced an alternative image. Jones reported that whereas HM used mental images as a mnemonic strategy, they were forgotten just as the words themselves were forgotten. Unlike $\mathrm{HM}$, however, the clinically diagnosed AD patients in the current study were likely to have some loss of semantic memory in addition to episodic memory impairment (Blackwell et al., 2004; Hodges \& Patterson, 1995), and as a result the imageable information they may have drawn on to facilitate encoding of concrete stimuli may not have been as semantically rich as that available for the healthy elderly. Several studies have reported that verbal PAL performance by $\mathrm{AD}$ patients is affected to some degree by a breakdown in the structure of, or relationships within, semantic memory (Granholm \& Butters, 1988; McWalter et al., 1991; Salmon et al., 1988; Spaan et al., 2005). The advantage of verbal variants of the PAL paradigm may be that they allow for the assessment of separate arbitrary and semantic aspects of memory within the one task (Elwood, 1997), without having to administer multiple neuropsychological tasks to capture both domains.

This study raises a variety of additional questions and provides multiple avenues for future research. It will be essential to determine whether a verbal associate-recognition task can discriminate early AD patients from those with retrieval based-memory impairment, such as patients with subcortical forms of dementia. One aim of the current study was to recruit a sample of elderly depressed patients with subjective memory impairment to investigate this issue using the verbal associate-recognition test. However, the aim was not fulfilled because of the difficulty of confidently excluding the presence of very early AD in many older adults with depression. Future research may benefit from recruiting younger people aged 40 to 60 years who are unlikely to have early $\mathrm{AD}$, but who have memory impairment from conditions such as depression or Parkinson's disease, which do not primarily affect MTL functioning.

\section{ACKNOWLEDGMENTS}

For assistance with patient recruitment the authors acknowledge the support of Ms. Jennine Melville, Manager, Cognitive Dementia and Memory Service (CDAMS), Kingston Centre, Southern Health, Victoria. For assistance with statistical analyses the authors acknowledge Dr. Simon Moss, School of Psychology, Psychiatry and Psychological Medicine, Monash University, Clayton.

\section{REFERENCES}

Aggleton, J.P. \& Shaw, C. (1996). Amnesia and recognition memory: A re-analysis of psychometric data. Neuropsychologia, 34, 51-62.

Albert, M.S. (1981). Geriatric neuropsychology. Journal of Consulting \& Clinical Psychology, 49, 835-850.

Benedict, R.H.B., Schretlen, D., Gronigner, L., \& Brandt, J. (1998). Hopkins Verbal Learning Test-Revised: Normative data and analysis of inter-form and test-retest reliability. Clinical Neuropsychologist, 12, 43-55.

Blackwell, A.D., Sahakian, B.J., Vesey, R., Semple, J.M., Robbins, T.W., \& Hodges, J.R. (2004). Detecting dementia: Novel neuropsychological markers of preclinical Alzheimer's disease. Dementia \& Geriatric Cognitive Disorders, 17, 42-48.

Braak, H. \& Braak, E. (1991). Neuropathological staging of Alzheimer-related changes. Acta Neuropathologica, 82, 239-259. 
Brookmeyer, R., Gray, S., \& Kawas, C. (1998). Projections of Alzheimer's disease in the United States and the public health impact of delaying disease onset. American Journal of Public Health, 88, 1337-1342.

Bunce, D. (2003). Cognitive support at encoding attenuates age differences in recollective experience among adults of lower frontal lobe function. Neuropsychology, 17, 353-361.

Burke, D.M. \& Light, L.L. (1981). Memory and aging: The role of retrieval processes. Psychological Bulletin, 90, 513-546.

Burke, W.J., Roccaforte, W.H., \& Wengel, S.P. (1991). The short form of the Geriatric Depression Scale: A comparison with the 30-item form. Journal of Geriatric Psychiatry and Neurology, 4, 173-178.

Butters, N., Wolfe, J., Martone, M., Granholm, E., \& Cermak, L.S. (1985). Memory disorders associated with Huntington's disease: Verbal recall, verbal recognition and procedural memory. Neuropsychologia, 23, 729-743.

Chen, P., Ratcliff, G., Belle, S.H., Cauley, J.A., DeKosky, S.T., \& Ganguli, M. (2000). Cognitive tests that best discriminate between presymptomatic $\mathrm{AD}$ and those who remain nondemented. Neurology, 55, 1847-1853.

Cohen, N.J. \& Eichenbaum, H. (1993). Memory, Amnesia, and the Hippocampal System. Cambridge, MA: The MIT Press.

Cohen, N.J., Ryan, J., Hunt, C., Romine, L., Wszalek, T., \& Nash, C. (1999). Hippocampal system and declarative (relational) memory: Summarizing the data from functional neuroimaging studies. Hippocampus, 9, 83-98.

Dalla Barba, G. (1997). Recognition memory and recollective experience in Alzheimer's disease. Memory, 5, 657-672.

Davachi, L. (2006). Item, context and relational episodic encoding in humans. Current Opinion in Neurobiology, 16, 693-700.

Dunlosky, J. \& Hertzog, C. (1998). Aging and deficits in associative memory: What is the role of strategy production? Psychology \& Aging, 13, 597-607.

Elias, M.F., Beiser, A., Wolf, P.A., Au, R., White, R.F., \& D’Agostino, R.B. (2000). The preclinical phase of Alzheimer disease: A 22-year prospective study of the Framingham Cohort. Archives of Neurology, 57, 808-813.

Elwood, R.W. (1997). Episodic and semantic memory components of verbal paired-associate learning. Assessment, 4, 73-77.

Folstein, M.F., Folstein, S.E., \& McHugh, P.R. (1975). "MiniMental State": A practical way of grading the cognitive state for the clinician. Journal of Psychiatric Research, 12, 189-198.

Fowler, K.S., Saling, M.M., Conway, E.L., Semple, J.M., \& Louis, W.J. (2002). Paired associate performance in the early detection of DAT. Journal of the International Neuropsychological Society, 8, 58-71.

Gallo, D.A., Sullivan, A.L., Daffner, K.R., Schacter, D., \& Budson, A.E. (2004). Associative Recognition in Alzheimer's Disease: Evidence for Impaired Recall-to-Reject. Neuropsychology, $18,556-563$.

Giacobini, E. (2001). Do cholinesterase inhibitors have diseasemodifying effects in Alzheimer's disease? CNS Drugs, 15, 85-91.

Golinkoff, M. \& Sweeney, J.A. (1989). Cognitive impairments in depression. Journal of Affective Disorders, 17, 105-112.

Grady, C.L., Haxby, J.V., Horwitz, B., Sundaram, M., Berg, G., Schapiro, M., Friedland, R.P., \& Rapoport, S.I. (1988). Longitudinal study of the early neuropsychological and cerebral metabolic changes in dementia of the Alzheimer type. Journal of Clinical \& Experimental Neuropsychology, 10, 576-596.
Granholm, E. \& Butters, N. (1988). Associative encoding and retrieval in Alzheimer's and Huntington's disease. Brain \& Cognition, 7, 335-347.

Greenaway, M.C., Lacritz, L.H., Binegar, D., Weiner, M.F., Lipton, A., \& Cullum, C. (2006). Patterns of verbal memory performance in mild cognitive impairment, Alzheimer disease, and normal aging. Cognitive and Behavioral Neurology, 19, 79-84.

Greene, J.D., Baddeley, A.D., \& Hodges, J.R. (1996). Analysis of the episodic memory deficit in early Alzheimer's disease: Evidence from the doors and people test. Neuropsychologia, 34, $537-551$

Gronlund, S.D. \& Ratcliff, R. (1989). Time course of item and associative information: Implications for global memory models. Journal of Experimental Psychology: Learning, Memory, \& Cognition, 15, 846-858.

Henke, K., Buck, A., Weber, B., \& Wieser, H.G. (1997). Human hippocampus establishes associations in memory. Hippocampus, 7, 249-256.

Hodges, J. (1998). The amnestic prodrome of Alzheimer's disease. Brain, 121, 1601-1602.

Hodges, J.R. \& Patterson, K. (1995). Is semantic memory consistently impaired early in the course of Alzheimer's disease? Neuroanatomical and diagnostic implications. Neuropsychologia, 33, 441-459.

Hodges, J.R. (2000). Memory in the dementias: With special reference to Alzheimer's disease and semantic dementia. In E. Tulving \& F. Craik (Eds). Handbook of memory. Oxford: Oxford University Press, 441-459.

Howard, D.V., Fry, A.F., \& Brune, C.M. (1991). Aging and memory for new associations: Direct versus indirect measures. Journal of Experimental Psychology: Learning, Memory, \& Cognition, 17, 779-792.

Hyman, B.T., Van Hoesen, G.W., Kromer, L.J., \& Damasio, A.R. (1986). Perforant pathway changes and the memory impairment of Alzheimer's disease. Annals of Neurology, 20, 472-481.

Jones, M.K. (1974). Imagery as a mnemonic aid after left temporal lobectomy: Contrast between material-specific and generalized memory disorders. Neuropsychologia, 12, 21-30.

Karlsson, T., Johansson, I., Adolfsson, R., Nilsson, L., \& Dubuc, S. (2003). Recognition memory in Alzheimer's disease: A demonstration of a remarkable memory capacity in Alzheimer's disease. Dementia and Geriatric Cognitive Disorders, 15, 6-9.

Kinsbourne, M. \& Winocur, G. (1980). Response competition and interference effects in paired-associate learning by Korsakoff amnesics. Neuropsychologia, 18, 541-548.

Lachner, G., Satzer, W., \& Engel, R. (1994). Verbal memory tests in the differential diagnosis of depression and dementia: Discriminative power of seven test variations. Archives of Clinical Neuropsychology, 9, 1-13.

Lee, A. C., Rahman, S., Hodges, J. R., Sahakian, B. J., \& Graham, K. S. (2003). Associative and recognition memory for novel objects in dementia: Implications for diagnosis. European Journal of Neuroscience, 18, 1660-1670.

Leentjens, A.F.G., Verhey, F.R.J., Lousberg, R., Spitsbergen, H., \& Wilmink, F.W. (2000). The validity of the Hamilton and Montgomery-Åsberg depression rating scales as screening and diagnostic tools for depression in Parkinson's disease. International Journal of Geriatric Psychiatry, 15, 644-649.

Lipinska, B. \& Backman, L. (1997). Encoding-retrieval interactions in mild Alzheimer's disease: The role of access to categorical information. Brain \& Cognition, 34, 274-286. 
Locascio, J.J., Growdon, J.H., \& Corkin, S. (1995). Cognitive test performance in detecting, staging, and tracking Alzheimer's disease. Archives of Neurology, 52, 1087-1099.

Lowndes, G.J. \& Savage, G.R. (2007). Early detection of memory impairment in early Alzheimer's disease: A neurocognitive perspective on assessment. Neuropsychological Review, 17, 193-202.

Mayes, A.R., Holdstock, J.S., Isaac, C.L., Hunkin, N.M., \& Roberts, N. (2002). Relative sparing of item recognition memory in a patient with adult-onset damage limited to the hippocampus. Hippocampus, 12, 325-340.

Mayes, A.R., Holdstock, J.S., Isaac, C.L., Montaldi, D., Grigor, J., Gummer, A., Cariga, P., Downes, J.J., Tsivilis, D., Gaffan, D., \& Norman, K.A. (2004). Associative recognition in a patient with selective hippocampal lesions and relatively normal item recognition. Hippocampus, 14, 763-784.

McKhann, G., Drachman, D., Folstein, M., Katzman, R., Price, D., \& Stadlan, E.M. (1984). Clinical diagnosis of Alzheimer's disease: Report of the NINCDS-ADRDA Work Group under the auspices of Department of Health and Human Services Task Force on Alzheimer's Disease. Neurology, 34, 939-944.

McWalter, G.J., Montaldi, D., Bhutani, G.E., \& McCrory, S. (1991). Paired associate verbal learning in dementia of Alzheimer's type. Neuropsychology, 5, 205-211.

Michel, J.P., Zekry, D., Mulligan, R., Giacobini, E., \& Gold, G. (2001). Economic considerations of Alzheimer's disease and related disorders. Aging (Milano), 13, 255-260.

Montaldi, D., Spencer, T.J., Roberts, N., \& Mayes, A.R. (2006). The neural system that mediates familiarity memory. Hippocampus, 16, 504-520.

Montgomery, S.A. \& Asberg, M. (1979). A new depression scale designed to be sensitive to change. British Journal of Psychiatry, 134, 382-389.

Mormont, E., Laurier-Grymonprez, L., Baisset-Mouly, C., \& Pasquier, F. (2003). The profile of memory disturbance in early Lewy body dementia differs from that in Alzheimer's disease. Revue Neurologique, 159, 762-766.

Nelson, H.E. \& Willison, J. (1991). National Adult Reading Test (NART): Test manual (2nd ed.). Windsor, UK: NFER Nelson.

Nobel, P.A. \& Shiffrin, R.M. (2001). Retrieval processes in Recognition and Cued Recall. Journal of Experimental Psychology: Learning, Memory, \& Cognition, 27, 384-413.

Norman, K.A. \& O'Reilly, R.C. (2003). Modelling hippocampal and neocortical contributions to recognition memory: A complementary-learning-systems approach. Psychological Review, 110, 611-646.

Paivio, A. (1991). Dual coding theory: Retrospect and current status. Canadian Journal of Psychology, 45, 255-287.

Paivio, A., Khan, M., \& Begg, I. (2000). Concreteness and relational effects on recall of adjective-noun pairs. Canadian Journal of Experimental Psychology, 54, 149-160.

Piercy, M. \& Huppert, G.A. (1972). Efficient recognition of pictures in organic amnesia. Nature, 240, 564.

Quamme, J.R., Yonelinas, A.P., Widaman, K.F., Kroll, N.E., \& Sauve, M.J. (2004). Recall and recognition in mild hypoxia: Using covariance structural modelling to test competing theories of explicit memory. Neuropsychologia, 42, 672-691.

Reed, J.M. \& Squire, L.R. (1997). Impaired recognition memory in patients with lesions limited to the hippocampal formation. Behavioral Neuroscience, 111, 667-675.

Ribeiro, F., Guerreiro, M., \& De Mendonca, A. (2007). Verbal learning and memory deficits in mild cognitive impairment.
Journal of Clinical \& Experimental Neuropsychology, 29, 187-197.

Salmon, D.P., Shimamura, A.P., Butters, N., \& Smith, S. (1988). Lexical and semantic priming deficits in patients with Alzheimer's disease. Journal of Clinical and Experimental Neuropsychology, 10, 477-494.

Salmond, C.H., Chatfield, D.A., Menon, D.K., Pickard, J.D., \& Sahakian, B.J. (2005). Cognitive sequelae of head injury: Involvement of basal forebrain and associated structures. Brain, 128, 189-200.

Salthouse, T.A. (1994). Aging associations: Influence of speed on adult age differences in associative learning. Journal of Experimental Psychology: Learning, Memory, \& Cognition November, 20, 1486-1503.

Salthouse, T.A. (1995). Selective influences of age and speed on associative memory. American Journal of Psychology, 108, 381-396.

Savage, G.R., Saling, M.M., Davis, C.W., \& Berkovic, S.F. (2002). Direct and indirect measures of verbal relational memory following anterior temporal lobectomy. Neuropsychologia, 40, 302-316.

Spaan, P.E.J., Raaijmakers, J.G.W., \& Jonker, C. (2005). Neuropsychology, 19, 629-640.

Squire, L.R. \& Shimamura, A.P. (1986). Characterizing amnesic patients for neurobehavioral study. Behavioral Neuroscience, $100,866-877$.

Swainson, R., Hodges, J.R., Galton, C.J., Semple, J., Michael, A., Dunn, B.D., Iddon, J.L., Robbins, T.W., \& Sahakian, B.J. (2001). Early detection and differential diagnosis of Alzheimer's disease and depression with neuropsychological tasks. Dementia \& Geriatric Cognitive Disorders, 12, 265-280.

Tierney, M.C., Black, S.E., Szalai, J.P., Snow, W.G., Fisher, R.H., Nadon, G., \& Chui, H.C. (2001). Recognition memory and verbal fluency differentiate probable Alzheimer disease from subcortical ischemic vascular dementia. Archives of Neurology, 58, 1654-1659.

Tierney, M.C., Szalai, J.P., Snow, W.G., Fisher, R.H., Nores, A., Nadon, G., Dunn, E., \& St. George-Hyslop, P.H. (1996). Prediction of probable Alzheimer's disease in memory-impaired patients: A prospective longitudinal study. Neurology, 46, 661-665.

Tulving, E. \& Markowitsch, H.J. (1998). Episodic and declarative memory: Role of the hippocampus. Hippocampus, 8 , 198-204.

Vargha-Khadem, F., Gadian, D.G., Watkins, K.E., Connelly, A., Van Paesschen, W., \& Mishkin, M. (1997). Differential effects of early hippocampal pathology on episodic and semantic memory. Science, 277, 376-380.

Wallenstein, G.V., Eichenbaum, H., \& Hasselmo, M.E. (1998). The hippocampus as an associator of discontiguous events. Trends in Neurosciences, 21, 317-323.

Wechsler, D. (1997). Wechsler Adult Intelligence Scale, Third Edition. San Antonio, TX: The Psychological Corporation.

Welsh, K., Butters, N., Hughes, J., Mohs, R., \& Heyman, A. (1991). Detection of abnormal memory decline in mild cases of Alzheimer's disease using CERAD neuropsychological measures. Archives of Neurology, 48, 278-281.

Welsh, K.A., Butters, N., Mohs, R.C., Beekly, D., Edland, S., Fillembaum, G., \& Heyman, A. (1994). The Consortium to Establish a Registry for Alzheimer's Disease (CERAD): A normative study of the neuropsychological battery. Neurology, 44, 609-614. 
Westerberg, C.E., Paller, K.A., Weintraub, S., Mesulam, M.M., Holdstock, J.S., Mayes, A.R., \& Reber, P.J. (2006). When memory does not fail: Familiarity-based recognition in mild cognitive impairment and Alzheimer's disease. Neuropsychology, 20, 193-205.

Wixted, J.T. \& Squire, L.R. (2004). Recall and recognition are equally impaired in patients with selective hippocampal damage. Cognitive, Affective \& Behavioral Neuroscience, 4, 58-66.

Yesavage, J.A., Brink, T.L., Rose, T.L., Lum, O., Huang, V., Adey, M., \& Leirer, V. (1983). Development and validation of a geriatric depression screening scale: A preliminary report. Journal of Psychiatric Research, 39, 37-49.

Yonelinas, A.P. (1994). Receiver-operating characteristics in recognition memory: Evidence for a dual-process model. Journal of Experimental Psychology: Learning, Memory, \& Cognition, 20, 1341-1354.
Yonelinas, A.P. (1997). Recognition memory ROCs for item and associative information: The contribution of recollection and familiarity. Memory \& Cognition, 25, 747-763.

Yonelinas, A.P. (2001). Consciousness, control, and confidence: The 3 Cs of recognition memory. Journal of Experimental Psychology: General, 130, 361-379.

Yonelinas, A.P., Hopfinger, J.B., Buonocore, M.H., Kroll, N.E., \& Baynes, K. (2001). Hippocampal, parahippocampal and occipital-temporal contributions to associative and item recognition memory: An fMRI study. Neuroreport, 12, 359-363.

Zec, R.F. (1993). Neuropsychological functioning in Alzheimer's disease. In R.W. Parks, R.F. Zec, \& R.S. Wilson (Eds.), Neuropsychology of Alzheimer's disease and other dementias (pp. 380). New York: Oxford University Press. 